\title{
Pincuk Sebagai Metode Penetapan Harga Jual (Studi Fenomenologi Pada Penjual Nasi Pecel Di Blitar)
}

\author{
Agustyas Retno Hernani1, Endah Masrunik²
}

1Fakultas Ekonomi Universitas Islam Balitar, tyasretno824@gmail.com

2Fakultas Ekonomi Universitas Islam Balitar, endahmasrunik@gmail.com

\begin{tabular}{|c|c|}
\hline ARTICLE INFO & Abstract \\
\hline $\begin{array}{l}\text { Article History: } \\
\text { Accepted : } 2021 \\
\text { Fixed : } 2021 \\
\text { Approved : } 2021 \\
\text { Keywords: } \\
\text { Qualitative; Selling Price } \\
\text { Determinatio; Pincuk Method. }\end{array}$ & $\begin{array}{l}\text { This study aims to determine the phenomena that occur or are carried out by } \\
\text { pecel rice sellers in determining the cost of selling pecel rice. Pincuk itself is a } \\
\text { container made of banana leaves in the shape of a cone and used to wrap rice. } \\
\text { In this study using qualitative methods of phenomenology, and primary data } \\
\text { sources. Where this research focuses on analyzing the phenomena, actions or } \\
\text { behavior of pecel rice sellers in setting the selling price. The results of this } \\
\text { study indicate that the determination of the selling price is not only a } \\
\text { reflection of the cost of goods sold, but there are other phenomena that create } \\
\text { characteristics such as the use of the pincuk method. In determining a selling } \\
\text { price with pincuk, use human instinct to measure and weigh by hand all } \\
\text { components in each pincuk during the compounding process. So that the } \\
\text { elements of production costs in each pincuk are different, but the selling price } \\
\text { per pincuk is the same. And when there is an increase in the ingredients for } \\
\text { pecel pincuk, the seller also does not increase the price. However, it will } \\
\text { slightly reduce the size of the pincuk pecel component. }\end{array}$ \\
\hline & Abstraks \\
\hline $\begin{array}{l}\text { Kata Kunci: } \\
\text { Kualitatif; Penetapan Harga } \\
\text { Jual; Metode Pincuk } \\
\text { DOI: }\end{array}$ & $\begin{array}{l}\text { Penelitian ini bertujuan guna mengetahui fenomena-fenomena yang } \\
\text { terjadi atau yang dilakukan oleh penjual nasi pecel dalam menentukan } \\
\text { harga pokok penjualan nasi pecel. Pincuk sendiri merupakan wadah } \\
\text { yang terbuat dari daun pisang yang di bentuk kerucut dan digunakan } \\
\text { untuk membungkus nasi. Dalam penelitian ini menggunakan metode } \\
\text { kualitatif fenomenologi, dan sumber data primer. Dimana penelitian } \\
\text { ini berfokus pada analisa terhadap fenomena-fenomena, tindakan- } \\
\text { tindakan atau tingkah laku penjual nasi pecel dalam menetapkan } \\
\text { harga jual. Dari hasil penelitian ini menunjukkah bahwa penetapan } \\
\text { harga jual bukan hanya cerminan dari harga pokok penjualan, namun } \\
\text { terdapat fenomena-fenomena lain yang menciptakan ciri khas seperti } \\
\text { dalam penggunaan metode pincuk. Dalam penetapan sebuah harga } \\
\text { jual dengan pincuk memanfaatkan insting manusia untuk menakar } \\
\text { serta menimbang menggunakan tangan semua komponen disetiap } \\
\text { pincuknya saat proses peracikan. Sehingga unsur-unsur cost produksi } \\
\text { dalam setiap pincuknya berbeda, namun harga jual per pincuknya } \\
\text { sama. Dan ketika terjadi kenaikan dari bahan-bahan pecel pincuk, } \\
\text { penjual juga tidak menaikkan harga. Namun akan sedikit mengurangi } \\
\text { besarnya komponen pecel pincuk. }\end{array}$ \\
\hline
\end{tabular}




\section{Pincuk Sebagai Metode Penetapan Harga Jual ...}

Agustyas Retno Hernani. Endah Masrunik

Correspondence:

Name: Endah Masrunik

Email: endahmasrunik@gmail.com

ISSN: 2355-9543 (Print)

ISSN: 2460-3775 (Online)

\section{INTRODUCTION}

Kemajemukan akan menciptakan sebuah kekayaan. Bhinneka Tunggal Ika yang bukan hanya semboyan semata, ia merupakan representasi dari banyaknya perbedaan di Indonesia. Perbedaan letak geografis, suku, agama, perilaku sosial serta aturan adat yang ada dalam masyarakat akan menciptakan budaya. Budaya merupakan salah satu warisan leluhur yang mengandung sebuah nilai edentitas suatu wilayah dan berkembang sesuai dengan perkembangan kehidupan manusia itu sendiri. Menurut Prayogi \& Danial, (2016)wujud budaya sesungguhnya meliputi 3 macam yaitu ide, tindakan dan artefak.Kuliner merupakan salah satu produk budaya, dewasa ini modernisasi sudah mulai mengikis ketradisionalan menjadi "kebaratbaratan". Namun masih tak jarang ditemui makanan atau kuliner yang mengandung unsur tradisional, yakni mulai dari alat dan bahan, cara pengolahan, bahkan dalam penyajiannya pun masih terdapat unsur kedaerahan dan mengandung identitas sebuah bangsa. Secara etimologis kuliner adalah terjemahan dari kata 'culinary' dalam Bahasa Inggris. Kata tersebut berasal dari bahasa Latin 'culinarius' yang didapat dari kata 'culina' yang berarti dapur yakni tempat memasak makanan(Utami, 2018). Memasak bisa diartikan sebagai mengolah bahan mentah menjadi bahan jadi yang siap dikonsumsi. Nasi pecel merupakan makanan tradisional yang lazim ditemui. Perpaduan dari olahan hasil alam serta sentuhan ketradisionalan baik dalam proses pengolahan maupun penyajiannya menciptakan sebuah kuliner khas Indonesia.Usaha mikro, kecil, dan menengah kian hari kian menjamur, banyak sekali usaha rumahan maupun kaki lima bergerak di bidang kuliner, diantaranya yaitu penjual pecel pincuk. Sebagai penggiat usaha, penentuan harga menjadi hal yang sangat vital. Analisis biaya pokok penjualan harus dihitung dengan seksama. Penentuan biaya berkaitan erat dengan penentuan harga jual agar menghasilkan laba yang sesuai sehingga usaha dapat berlangsung dengan lancar, namun nyatanya dilapang terdapat fenomena unik yang berbenturan dengan teori keilmuan. Selain itu pesaing juga menjadi faktor kunci keberhasilan usaha, selisih biaya antar pengusaha serupa akan mempengaruhi ketertarikan pelanggan. Rego nggowo rupo salah satu peribahasa Jawa yang bermakna ada harga ada rupa, semakin harganya tinggi maka kualitas dan kuantitas barang semakin baik pula. Namun sebagai konsumen tentu mengaharapkan kualitas dan kualitas lebih baik namun dengan harga yang murah. Maka dari itu dibutuhkan strategi dalam penetapan harga jual yang tepat. Sehingga mampu bersaing dan dapat mengakomodasi seluruh biaya yang terjadi.Biaya adalah merupakan pengorbanan sumber ekonomi yang diukur dalam satuan uang, yang telah terjadi atau kemungkinan akan terjadi untuk tujuan tertentu(Mulyadi, 2010). Jadi, biaya merupakan sejumlah uang yang dikorbankan oleh badan usaha guna memproduksi barang atau jasa yang bernilai jual.

Di era modern ini biaya merupakan hal pokok dalam proses kegiatan jual beli atau pemanfaatan jasa. Biaya yang dimaksudkan disini bukan hanya untuk benda berwujud namun juga untuk tenaga yang dikeluarkan oleh produsen apabila kegiatan tersebut terjadi dalam perusahaan jasa.

Faktor biaya menjadi perhatian khusus pengambil keputusan dalam rangak menetapkan keputusan terkait harga jual. Pengorbanan yang dilakukan oleh perusahaan harus mampu ditutupi oleh harga jual produk yang dihasilkan, maka dari itu batas bawah penentuan harga jual yaitu faktor biaya agar dapat menghasilkan laba yang diinginkan. Oleh karenanya dapat diasumsikan bahwa agar tetap memperoleh laba, harga jual suatu produk tidak boleh lebih rendah daripada total biaya yang telah dikorbankan oleh perusahaan.Harga jual merupakan suatu imbal balik berupa satuan moneter yang dikeluarkan oleh konsumen atau pengguna jasa dalam rangka mengganti apa yang telah dikorbankan oleh produsen atau penyedia jas(Mulyadi, 2010). Didalam sebuah harga jual telah terkandung laba yang merupakan hasil dari pengurangan pendapatan dengan total biaya yang dikeluarkan oleh produsen atau penyedia jasa. Maka dari itu kedua komponen tersebut yaitu sangat erat kaitannya karena harga berpengaruh secara langsung terhadap laba. Dalam penentuannya, keputusan mengenai harga jual tidak jarang dilakukan berulang-ulang, hal tersebut dikarenakan harga jual dipengaruhi beberapa hal 
baik internal maupun eksternal. Maka dari itu harga jual harus mencerminkan biaya-biaya saat ini serta faktor-faktor yang mempengaruhinya.Harga jual menciptakan sebuah citra terhadapa produk. Selain terkait biaya-biaya dikeluarkan guna memproduksi barang atau jasa, harga jual juga harus mencangkup kualitas sebuah barang. Harga

\section{METHOD}

Jenis penelitian yang digunakan yaitupenelitian kualitatif yang merupakan penelitian yang bertujuan guna memahami fenomenafenomenatentang hal yang dialami atau dilakukan oleh subyek di lokasi penelitian(Moleong, 2018). Subjek dalam penelitian ini yaitu penjual nasi pecel di blitar yang menggunakan metode pincuk dalam penetapan harga jual. Tehknik pengumpulan data dalam penelitian ini yaitu menggunakan metode observasi dan wawancara. Dimana peniliti secara aktif berpartisipasi dalam kegiatan penjualan pecel pincuk di Blitar serta melakukan wawancara kepada penjual pecel pincuk maupun dengan pembeli

\section{RESULTS}

Musim pandemic covid-19 membuat sebagian besar manusia menjadi lebih protektif terhadap kehigienisan makanan. Baik itu yang diolah sendiri maupun makanan yang dibeli. Tidak luput juga dengan penjual nasi pecel. Yang saat ini juga lebih memperhatikan akan wadah yang digunakan untuk membungkus barang jualannya. Pecel yang dulu di bungkus dengan daun pisang berbentuk kerucut dengan sematan lidi yang digunakan sebagai penyatu kedua sisi, kini teah bergeser atau digantikan dengan kertas bungkus yang dianggap lebih praktis dan higienis. Sehinggapincuk menggunakan daun pisang cukup jarang ditemukan, daun pisang telah digantikan dengan kertas yang diciptakan khusus sebagai alas dan pembungkus makanan. Sehingga cost dari harga jual pecel pincuk ini mengalami kenaikan, dimana yang dulu pecel pincuk dibungkus menggunakan daun pisang dan sematan lidi yang di dapatkan tanpa harus mengeluarkan biaya, kini harus mengeluarkancost untuk membeli bungkus atau pincuk dari kertas bungkus tersebut.

\section{DISCUSSION}

Harga jual merupakan suatu imbal balik berupa satuan moneter yang dikeluarkan oleh konsumen atau pengguna jasa dalam rangka mengganti apa yang telah dikorbankan oleh produsen atau penyedia jasa baik dalam hal jual sangat mempengaruhi keputusan konsumen dalam membeli, dewasa ini masyarakat cenderung menginginkan harga produk yang rendah dengan kualitas yang tinggi, maka dari itu penetapan sebuah harga jual menjadi hal pokok dalam memasarkan sebuah produk.

materiel maupun immaterial. Didalam sebuah harga jual telah terkandung laba yang merupakan hasil dari pengurangan pendapatan dengan total biaya yang dikeluarkan oleh produsen maka dari itu harga jual harus mampu menutup biaya produksi agar produsen tidak mengalami kerugian.

Dalam menetapkan harga jual pecel pincuk, para penjual pecel pincuk tidak menghitung seluruh cost yang telah di keluarkan, namun hanya menghitung beberapa cost yang nilainya dianggap besar hal ini senada dengan penelitian (Efendi, 2018)perhitungan harga pokok produksi dan harga jual belum menggunkan dasar perhitungan secara benar serta jumlah biaya-biaya yang dalokasikan hanya berdasarkan asumsi. Misalnya saja cost untuk pembelian beras yang diolah menjadi nasi, cost pembelian lauk pauk dan cost untuk olahan sambel pecel. Namun dari segi penetapan harga jual pecel pincuk, yang di dalam pecel pincuk terdapat, nasi, sayur (biasanya terdiri dari sawi/bayam, kacang, kangkung dan kecambah), serta lauk tempe, tahu, bregedel dan peyek, penjual tidak akan menambah atau menaikan harga jual apabila konsumen atau pembeli meminta penjual untuk menambah nasi ataupun sayur dan sambalnya. Penjual hanya akan menambah harga jualnya ketika pembeli meminta tambahan untuk lauknya. Sehingga dari hal ini cost yang dihasilkan untuk setiap pincuk pecelnya aan berbeda walaupun harga jualnya sama.Selain itu takaran setiap penjual juga berbeda, beberapa alat yang digunakan untuk menakar dalam menjual pecel pincuk diantaranya yaitu, enthong, jumput tangan serta sendok. Enthong digunakan untuk menakar produk intinya yaitu nasi, walaupun dengan enthong jumlah atau berat nasi tidak sama antar pincuk atau terdapat selisih, namun selisih ini tidak besar, sehingga hal ini dimaklumi oleh pembeli, baik penjual ataupun pembeli sama-sama ikhlas dengan adanya selisih tersebut. hal ini juga senada dengan penelitian (Wahyudi \& Masrunik, 2019)yang menyatakan bahwa enthong merupakan takaran yang pas, selisih yang terjadi tidak begitu besar sejalan juga dengan penelitian (Ilmiyati, 2018)bahwa pembeli ridho dengan harga sama 


\section{Pincuk Sebagai Metode Penetapan Harga Jual ... Agustyas Retno Hernani. Endah Masrunik}

walaupun porsi berbeda. Dan penggunaan enthong juga merupaka pertimbangan penjual dimana ketika dirumah semua orang ketika mengambil nasi untuk makan akan menggunakan enthong. Dan dalam 1 pincuk nasi pecel terdapat dua enthong nasi. Yang masing-masing pincuknya berat nasi tidak sama.Selain nasi unsur pecel pincuk yang kedua yaitu sayuran, dimana sayuran ini akan diletakkan tepat diatas nasi, yang ukuran atau timbangan dari sayuran itu adalah tangan penjual. Sayur akan di ambil dengan cara jumput tangan dan takarannya adalah perkiraan atau insting dari penjual hal ini senada dengan penelitian agustina, (2019)yang menyatakan bahwa dalam menentukan harga jual nasi krawu menggunakan proses Feeling atau perasaan. Penjual akan menyeimbangkan antara sayur yang di jumput dengan tangan dengan nasi yang dipincuk dalam tangan kiri, sehingga berat masingmasing porsi pincuk adalah hampir sama. Unsur berikutnya adalah sambel pecel. Yang ditakar dengan sendok dan disiramkan tepat diatas sayur. Untuk sambal pecel ini ukurannya adalah 3 sendok hingga 4 sendok makan, yang selanjutnya akan di tambahkan dengan kecambah yang takarannya adalah jumput tangan. Yang selanjutnya adalah lauk pauk.Harga jual yang ditetapkan untuk 1 pincuk pecel sebesar RP.7.000,-. Dalam sehari setiap penjual pecel pincuk mampu penjual antara 90 sampai 95 pincuk pecel. Harga jual Rp.7.000,00 tersebut sudah termasuk lauknya dan penjual tidak akan menaikkan harga jualnya walaupun pembeli minta tambahan nasi, sayur atau sambal. Kenaikan harga juga tidak akan dilakukan oleh penjual ketika ada kenaikan pada cost-cost yang timbul atas pecel pincuknya. Penjual hanya akan sedikit mengurangi takaran dari unsur-unsur pecel pincuknya. Penjual hanya akan menaikkan harga jual apabila pembeli meminta tambahan lauk. Besarnya kenaikan harga jual per pincuknya ditentukan oleh lauk yang dipilih untuk ditambah. Untuk setiap tambaha 1 tempe atau 1 tahu harga jual akan dinaikkan sebesar Rp.500,00, untuk setiap tambahan 1 bergedel dan 1 bungkus peyek, harga jual akan dinaikkan sebesar Rp.1.000,00. Setiap pincuk pecel jumlah unsur-unsurnya berbeda. Hal ini disesuaikan dengan kebutuhan dan keinginan pembeli. Adakalanya pembeli menginginkan sayur lebih banyak dari pada nasi, atau sebaliknya.Sehingga dari hal tersebut diatas dapat dilihat, bahwa harga jual yang ditetapkan tidak menghitung semua unsur cost produksi dan keuntungan yang ingin di dapatkan, dimana para penjual pecel pincuk tidak menghitung berapa cost tenaga kerja yang telah dikeluarkan sampai pecel pincuk siap di jual. Cost tenaga kerja dianggap tidak ada, karena anggota keluarga yang bertindak sebagai pekerja. Dan berjualan pecel pincuk digunakan untuk mencukupi semua anggota keluarga. serta penjual tidak menghitung cost lainnya seperti cost dari listrik, air maupun bahan bakar yang telah digunakan.Harga pokok penjualan bukan menjadi salah satu faktor penentu harga jual sebab pengaruh dari harga jual produk serupa oleh pesaing menjadi alasan yang sangat besar dalam menentukan keputusan harga jual. Sehingga walaupun para penjual tidak menghitung secara pasti harga jual yang seharusnya ditetapkan atas produk mereka, namun harga jual tersebut mampu bersaing dengan pesaing. Hal ini juga yang dilakukan oleh para penjual pecel pincuk di wilayah blitar. Dimana selain mempertimbangkan cost-cost yang telah dikeluarkan namun pejual pecel pincuk di blitar juga mempertimbangkan fenomena-fenomena yang terjadi serta dalam menentukan haga jual selain itu jug mempertimbangkan nilai-nilai religi yaitu sedekah, dengan menambah nasi atau sayur itu merupakan bagian dari sedekah penjual pecel pincuk sehingga penjual pecel pincuk tidak menaikkan harga pecel pincuknya hal ini senada dengan penelitian Amaliah \& Sugianto, (2018)dimana dalam penetapan harga jual, pedagang betawi bukan hanya melihat dari aspek ekonomi namun juga religi berupa sedekah dan nilai sosial.

\section{CONCLUSIONS}

Penetapan harga jual dengan metode pincuk tidak menghitung secara rinci cost-cost yang timbul dalam menjual nasi pecelnya. Penetapan harga jual dengan metode pincuk menyebbkan cost yang berbeda setiap pincuknya, hal ini di sebabkan dengan perbedaan takaran disetiap pincuk pecel yang dijualnya baik sengaja maupun tidak disengaja. Dalam kasus ketidaksengajaan, hal tersebut dapat terjadi karena dalam penakarannya hanya menggunakan enthong, jumput tangan serta sendok yang mengandalkan insting serta meminimalisir perbedaan dengan menimbang menggunakan tangan saat meraciknya. Selain itu pada kasus yang disengaja, karakter serta permintaan dari pembeli mempengaruhi banyaknya takaran nasi, sayuran maupun sambel serta lauk yang di inginkan pemebeli.

\section{REFERENCES}

agustina, vivani. (2019). Penentuan Harga Jual Nasi Krawu Buk Tiban dan Buk Wiwik 
Dengan Jumput Tangan Kabupaten Gresik: Sebuah Studi Fenomenologi,. A yan, 8(5), 55.

Amaliah, T. H., \& Sugianto, S. (2018). Konsep Harga Jual Betawian dalam Bingkai Si Pitung. Jurnal Akuntansi Multiparadigma, 9(1), 20-37. https://doi.org/10.18202/jamal.2018.04.9002

Efendi, R. A. (2018). Analisis Strategi Penetapan Harga Jual Ditinjau Dari Harga Pokok Produksi pada Perusahaan Alif Catering. Jurnal Manajemen Dan Start-Up Bisnis, 3(3), 1-8.

Ilmiyati, B. N. (2018). Tinjauan Hukum Islam Terhadap Penetapan Harga Sistem Prasmanan Di Rumah Makan Sederhana Sanparto Cindaga Kec. Kebasen Kab .... http://repository.iainpurwokerto.ac.id/4482 /

Moleong, L. J. (2018). Metodologi Penelitian Kualitatif, cet. In XI. Bandung: PT Remaja Rosdakarya.

Mulyadi. (2010). Akuntansi biaya (5th ed.). UPP STIM YKPN.
Prayogi, R., \& Danial, E. (2016). Pergeseran NilaiNilai Budaya Pada Suku Bonai Sebagai Civic Culture Di Kecamatan Bonai Darussalam Kabupaten Rokan Hulu Provinsi Riau. Humanika, $\quad 23(1)$, 61. https://doi.org/10.14710/humanika.23.1.6179

Utami, S. (2018). Kuliner Sebagai Identitas Budaya: Perspektif Komunikasi Lintas Budaya. CoverAge: Journal of Strategic Communication, 8(2), 36-44. https://doi.org/10.35814/coverage.v8i2.588

Wahyudi, A., \& Masrunik, E. (2019). PENENTUAN HARGA JUAL DENGAN METODE ENTONG PADA PENJUAL JENANG (Studi Fenomenologi Pada Penjual "Jenang" Desa Ngembul Kecamatan Binangun). AKUNTABILITAS: Jurnal Ilmiah Ilmu-Ilmu Ekonomi, 12(1), 72-81. https://doi.org/10.35457/akuntabilitas.v12i1. 772 